\title{
INMIGRACIÓN, FENÓMENO DE MILES DE FACETAS: ENFOQUE PARA UNA SANA CONVIVENCIA
}

\author{
IMMIGRATION, A MULTIFACETED PHENOMENON: AN \\ APPROACH ORIENTED TO FOSTER A HEALTHY CO-EXISTENCE
}

Dondomè-ib-lè Michel Ange Kambire Somda

Universidad Pablo de Olavide de Sevilla

e.mail: makamsom@upo.es
Recibido: julio de 2011

Aceptado: septiembre de 2011

Palabras clave: Movimientos migratorios, economía mundial, globalización mundial, competitividad, modelo neoliberal y profunda transformación.

Keywords: Migratory movements, world economy, world globalization, competitiveness, neoliberal model and deep transformation.

Resumen: A partir de los años 80 se inicia una profunda transformación de la economía mundial, y aparece un proceso de globalización económica basado en la extensión planetaria del comercio libre y en definir el principio de la competitividad como motor del desarrollo. Es cierto que este modelo neoliberal ha estimado límites hasta ahora no conocidos el intercambio del capital, bienes e información. Sin embargo, este desorden económico internacional se está desarrollando sobre un espacio planetario de enormes diferencias estructurales, sobre las que se imponen formas globales de organización social, económica y cultural que están resultando gravemente injustas, según demuestra la realidad. Por ello los diferentes movimientos de migraciones de trabajadores, refugiados y desplazados es una consecuencia clara de este modelo de desarrollo.

Abstract: From the 80 s there begins a deep transformation of the world economy, and there appears a process of economic globalization based on the planetary extension of the free trade and in defining the beginning of the competitiveness as motive of development. It is true that this neoliberal model has estimated up to limits till now not known the exchange of the capital, goods and information. Nevertheless, this economic international disorder is developing on a planetary space of enormous structural differences, on which there are imposed global forms of social, economic and cultural organization that are turning out to be seriously unjust, as the reality demonstrates. For it the different movements of workers' migrations, refugee and displaced it is a consequence. 


\section{l. Definición}

Inmigración y emigración, son dos términos que por su convergencia parecen tener el mismo sentido pero en la divergencia uno como otro tiene un sentido bien diferente. Ahora bien, vamos a ver lo que cada uno significa. En ambos, encontramos una acción y efecto de inmigrar y la llegada de extranjeros con objeto de establecerse en un país.

La diferencia principal entre la emigración y la inmigración sólo consiste en que el primer término se da a las personas que salen de un país y el segundo a las personas que entran en otro país. Así, a parte de lo expuesto acerca de emigración sólo nos pertenece examinar la acción de los gobiernos de los países que reciben los inmigrantes.

Si la inmigración toma únicamente el aspecto de turismo, hay algunos países que la miran con muy buenos ojos, y esta es el caso de Italia y Francia, que obtienen con ella ganancias por centenares de millones. Pero, en cambio, aumenta cada día las dificultades que oponen los gobiernos de Estados en permitir la inmigración de obreros. Existe en ella el peligro de exceso de trabajadores, motivando una depreciación en jornales, y esta ha sido la razón de las limitaciones. Incluso cuando la inmigración es favorable a un país en falta de manos de obra, caso actual de Francia, existen problemas políticos, morales y sociales de mucha importancia. Lo que en los Estados Unidos es un problema de raza, la enemistad secular de los blancos, los negros y los amarillos, en Europa es un problema de religión y de costumbres. Los emigrados e inmigrados no encuentran muchas veces el ambiente social que les es indispensable, y esta falta de adaptación determina que los obreros extranjeros, repartirlos en países y colocarlos, según sus aptitudes, en las regiones más indicadas. En Inglaterra no puede ser admitido ningún extranjero sin hallar antes ocupación y sin autorización del Ministerio de Trabajo, y debe inscribirse en un registro especial. En los Estados Unidos se aplica rigurosamente la Ley sobre la inmigración, señalándose cada año el número de emigrantes de cada país que pueden ser admitidos, restringiéndose cada vez más el contingente señalado. Como se da, a menudo, el caso de que por haberse rebasado en el numero de inmigrado, parece que hay tendencia a autorizar su entrada, prescindiendo del contingente señalado. Se ha publicado un derecho para inspeccionar la inmigración aérea.

\section{La naturaleza del fenómeno migratorio}

\section{2.l. Elemento estructural del sistema económico}

El fenómeno migratorio no es nuevo en la historia humana, pero en cada época adopta nuevas formas y caminos. Actualmente, la inmigración está unida de manera estructural a la economía de libre mercado, aunque no podemos olvidar las inmigraciones provocadas por regímenes políticos dictatoriales y por ciertas estructuras culturales y sociales de los pueblos. Las migraciones moder- 
nas tienen sus raíces en el mismo sistema económico dominante. No son un fenómeno coyuntural o pasajero. Por eso, no parece fácil que se puede prescindir de ellas en la estructura de los sistemas productivos actuales.

Es decir, que los procesos de internacionalización y concentración espacial del capital en determinadas aéreas geográficas, unidos a los procesos de dominación económica y de mantenimiento del subdesarrollo en otras, favorecen las migraciones de la fuerza de trabajo al servicio de las exigencias del desarrollo de los países industriales.

\subsection{Al servicio de la coyuntura económica}

Se puede afirmar que en Europa las migraciones se han venido concibiendo y tratando en primer lugar como un sistema general de aprovisionamiento de la obra necesaria para el desarrollo económico en la reconstrucción europea tras la II Guerra Mundial y, posteriormente, orientado el flujo migratorio hacia el sector terciario. Mano de obra, pues, al servicio de la coyuntura económica.

"A pesar de la existencia de altas tasas de desempleo, la configuración y fragmentación del mercado de trabajo provoca que existan" 'nichos laborales' que, por su precariedad, informalidad o naturaleza de la prestación, serán rechazados por los trabajadores nacionales $y$, en cambio, resultaran atrayentes para nuevos inmigrantes. Su presencia, en un mercado caracterizado por rigideces estructurales, introduce un factor de flexibilidad y representa una aportación, des- de el punto de vista productivo, nada despreciable». ${ }^{1}$

Esta concepción de la inmigración no es exclusiva de España, de manera que puede encontrarse perfectamente reflejada en los discursos políticos actuales y en muchas publicaciones de sectores de interesados. Por ejemplo:

"La inmigración es un medio de crear una cierta distensión sobre el mercado de empleo y de resistir a la presión social» (Georges POMPIDOU).

"La misma inmigración clandestina no es inútil ya que, si nos atuviéramos a la aplicación estricta de los reglamentos y acuerdos internacionales, tal vez nos faltara mano de obra» (Debate Asamblea nacional. Francia).

"La presencia de esta inmigración imprime agilidad a nuestra economía, al tratarse de gentes sin estabilidad, dispuestos a cambiar de ocupación, de región y, si llega el caso, a convertirse en parados indemnizados. La inmigración es también útil en la medida en que permite que nuestro país economice una parte de los gastos de capacidad (que corren en cargo del país de origen) y el regular mejor las cargas de la nación: por vía de prestaciones» (La Nueva Fábrica, Seminario patronal francés) ${ }^{2}$.

Sin embargo son muchos los que culpan a los inmigrantes del paro existente en los países de la UE. Ésta es una apreciación muy simplista y, además es falsa. Que pueden coexistir un alto índice de paro y al mismo tiempo un determinado porcentaje de empleo para los inmigrantes extranjeros se explica:

- Por la reestructuración del mercado de trabajo en función de la precarie- 
dad de los empleos. Todos los estudios que han realizado para ver la posibilidad de sustituir a los inmigrantes por los autónomos han concluido que hay muy poco margen para tal sustitución. Es decir, que los inmigrantes realizan aquellos trabajos que los del país ya no quieren hacer.

- Por el carácter no homogéneo del mercado de trabajo y la necesidad de poder disponer de un relativo excelente de mano de obra diferenciada en cuanto a sectores de producción, profesiones, calificaciones, sectores de actividad, niveles de empleo, etc.

- Por la disminución de la mano de obra local, que hace necesario recurrir a los trabajadores extranjeros. En general, en los países desarrollados, y concretamente en la UE, el mercado laboral tiende a contraerse y disminuir por agotamiento de la mano de obra agrícola, por el envejecimiento de la población activa y por la emigración de profesionales cualificados hacia zonas de inversión en el mundo.

Así pues, los inmigrantes no están únicamente porque ellos tengan necesidad, sino también porque Europa los necesita. Sin olvidar que incluso la necesidad de ir a trabajar en Europa nace de la dependencia de los países del Sur y de su progresivo empobrecimiento provocados por los propios intereses comerciales y geopolíticos europeos.

\subsection{Las causas de las migraciones}

Los mecanismos que ponen en marcha las migraciones, alimentadas por la concentración de la riqueza y de los medios de producción en determinadas aéreas geográficas son:
Económicos: deseos de lograr mejor empleo y mayores ingresos.

Culturales: disfrutar de más oportunidades de educación y de promoción.

De bienestar social: buscar mayores posibilidades de vivir mejor y disponer de mejores servicios.

Pero lo que sucede es que estos mecanismos, una vez puestos en marcha, continúan ejerciendo su función impulsora de la inmigración, independientemente de que la coyuntura económica sea de expansión o de crisis.

\subsection{Movimientos de población}

Las migraciones se planifican con una racionalidad meramente económica en función del crecimiento económico y de la realización rápida de beneficios. Raramente se tiene en cuenta el costo humano que suponen para quienes se ven forzados a abandonar su pueblo, su familia y su cultura, y menos dan se piensan en eliminar las causas profundas que provocan las injustas desigualdades entre países enriquecidos y empobrecidos.

"Se olvida a menudo que las migraciones son la mayor parte de las veces un pujante factor de desarrollo, no solamente para los mismos inmigrantes, sino también para los países y sociedades que los acogen, y algunas veces para los países de origen. Desde el punto de vista económico, las migraciones pueden ser un medio de repartir más eficazmente entre las regiones y los países el factor de producción y de consumo, esencial que es la mano de obra, contribuyendo así a alimentar y a reforzar el desarrollo y el cre- 
cimiento económicos. Resaltando que el mismo del modo la movilidad de mano de obra es a menudo un medio para operar las transferencias tecnológicas, se comprenderá el papel esencial jugado por el fenómeno migratorio en cuanto motor histórico del desarrollo» (Bernard Wood ${ }^{3}$.

En general, se define al inmigrante como trabajador manual, sin calificación profesional, que ocupa un puesto de trabajo duro y mal pagado, un empleo precario y temporal. Como un trabajador aislado, sin familia, destinado a regresar a su país; como un trabajador extranjero que, por ser extranjero, no disfruta del derecho al trabajo, ni tiene todos los derechos públicos, ni se busca su integración social.

Con sus políticas limitadas respecto al derecho a vivir en familia, a la residencia permanente, a obtener la nacionalidad y con sus resistencias a regularizar a cuantos están «sin papeles», es evidente que los países de la EU han optado formalmente por oponerse a la inmigración y por considerarla como simple movimiento económico y no como movimiento de población.

\section{Fenómeno permamente}

Concebida la migración como algo transitorio al servicio de la coyuntura económica, sin embargo se ha convertido en un fenómeno permanente. A pesar de las políticas restrictivas y de control de la UE, la inmigración ha ido asentándose en todos los países europeos gracias al aumento de la reagrupación familiar, por los matrimonios entre inmi- grantes y matrimonios mixtos, la obtención de la nacionalidad del país de residencia, por los permisos de residencia y de trabajo por tiempo ilimitado, etc.

La inmigración en España se presenta también, no como un fenómeno pasajero y temporal, sino como una permanencia a largo plazo. Aunque la mayoría tiene el proyecto de retornar, lo cierto es que terminan por instalarse definitivamente. Una permanencia que supone un costo social y un costo cultural de integración en la sociedad europea a tener en cuenta. Los inmigrantes se han convertido económica y socialmente en unos interlocutores necesarios para el diseño de las políticas de integración. Un camino de futuro debe ser cómo lograr que se contemplen a los inmigrantes no como trabajadores extranjeros con derechos limitados, sino como ciudadanos y trabajadores de pleno derecho.

\section{Aspectos positivos de la inmigración}

\section{4. l. La inmigración es una posi- bilidad, no un problema}

\begin{abstract}
Casi siempre se habla, se escribe, se legisla y se actúa mirando a la inmigración como fuente de problemas de todo tipo. Se habla de la «invasión tercermundista» y de masas hambrientas dispuestas a saltar sobre el bienestar europeo. Sin embargo, es posible contemplar la inmigración desde otras perspectivas mucho más integrales y positivas.
\end{abstract}




\section{1.l. La inmigración es un hecho social total}

Es decir, que actúa sobre todos los elementos que componen el cuerpo social. No trata únicamente de la dimensión laboral, de los movimientos del mercado de mano de obra. Ya no es como antes. Ahora crecen los flujos migratorios que pretenden instalarse en el número de inmigrantes de clase media, cuadros técnicos, estudiantes, etc. No es sólo una cuestión laboral, sino que también repercute en la enseñanza, la vivienda, la cultura, la identidad de los colectivos, la convivencia, el concepto de democracia, la vigencia de los derechos humanos, etc. Por lo tanto, no se pueden ofrecer respuestas y medidas unilaterales o simplistas de corte policial o de mero control de fronteras.

\subsubsection{La inmigración es un hecho de dimensiones planetarias}

Más de 120 millones de personas se mueven en estos flujos por todo el mundo. Son movimientos más de Sur a Sur que de Sur a Norte, como, según el tópico, siempre repiten algunos hablando de la lenta pero imparable «invasión» de Europa por los hambrientos del Tercer Mundo. Se dicen que la barca europea se puede hundir si se sube más gente y que cada país debe cerrar y vigilar bien sus fronteras. Sin embargo, la realidad es que la UE incluyendo las migraciones tiernas «soporta solamente el 15\% del total de población inmigrante del planeta».

Decir que la inmigración supone una grave amenaza para el espacio vital euro- peo es desconocer la realidad de que la inmigración está integrada hoy en una globalización de la economía al nivel mundial. Vivimos en una gran paradoja o contradicción: hay un sistema cerrado para el trabajo y abierto para el capital. Para explotar mejor la «mercancía trabajo» se utiliza el trabajo no declarado o clandestino de la llamada economía sumergida, donde la inmigración juega una importante función: trabajadores baratos, desprotegidos y dispuestos a ir de un lugar a otro, allí donde ubiquen el trabajo los dueños del capital, allí donde las condiciones sean más ventajosas para estos últimos. Es una forma de esclavitud: los inmigrantes son utilizados para realizar aquellos trabajos que los autóctonos no quieren hacer por las condiciones leoninas que imponen los empresarios y las multinacionales.

A partir de la década de los 80 se inicia una profunda transformación de la economía mundial, y aparece un proceso de globalización económica basado en la extensión planetaria del comercio libre y en definir el principio de la competitividad como motor del desarroIlo. Es cierto que este modelo neoliberal ha estimado hasta límites hasta ahora no conocidos el intercambio del capital, bienes e información (la aldea global, o mejor, el mercado global).

Sin embargo, este desorden económico internacional se está desarrollando sobre un espacio planetario de enormes diferencias estructurales, sobre las que se imponen formas globales de organización social, económica y cultural que están resultando gravemente injustas, según demuestra la realidad. Por eso, 
el actual movimiento mundial de trabajadores, refugiados y desplazados es una consecuencia clara de este modelo de desarrollo.

\section{2. Los aportes positivos de la inmigración}

En general, tanto en los medios de comunicación como en la opinión de la gente, existe una imagen muy negativa de los inmigrantes: «son competidores y fuente de problemas y lo mejor es que no vengan o que se vayan». A veces, cuando los europeos intentan sensibilizar a los suyos y hacer comprender a otros el tema de la inmigración, suelen usar argumentos tales como: «nosotros también fuimos emigrantes»... «ay que ser solidarios y respetar los derechos hu-manos»... «el mundo es para todos»... «explotamos al sur y nos aprovechamos de sus materias primas; por eso, debemos acoger a los inmigrantes que escapan de hambre que nosotros provocamos», etc.

Se trata casi siempre de recurrir a la Moral y a la Ética. Eso está bien, pero tales argumentos calan en ciertos oyentes. La clave estaría, además, en hacer descubrir la aportación de los inmigrantes. ¿Qué aportan a Europa? ¿Qué traen consigo? ¿Qué tienen de positivo?... Siendo conscientes de que ciertos argumentos tienen cierta dosis de cinismo, verbigracia:

\section{2.l. Nuestras sociedades envejecen y la inmigración rejuvenece a la población}

Aportando personas jóvenes a países con bajo crecimiento demográfico como, por ejemplo, España que tiene un índice de 0,3 hijos y que en el plazo de veinte años, perderá nueve millones de habitantes. Como indica esta noticia de prensa:

«Italia necesita más de emigrantes para sostener su economía». El contable general del Estado ha declarado que en los próximos 50 años Italia necesitará al menos 50.0000 emigrantes cada año para equilibrar las cotizaciones a la Seguridad Social y el PIB. En efecto, si se mantiene la actual tasa de fertilización, el año 2044 Italia pasará de 54 millones de habitantes actuales a sólo 44 millones, con una tasa elevada de envejecimiento el $11 \%$ de la población tendrá más de 80 años.

En un informe reciente del BBVA calculaba en 90.000 el número de trabajadores extranjeros que tendrán que incorporarse al mercado laboral español cada año de aquí al 2010 para mantener la actual tasa de población activa. Una disminución de la misma podría plantear problemas de desequilibrio entre activos y pasivos, especialmente si se mantiene el bajo Índice de natalidad de los últimos años a la vez que aumente la esperanza de vida. ${ }^{4}$ (EL País, 27-8-98).

\subsubsection{Los inmigrantes contribuyen a sostener sectores productivos en crisis}

Son creadores de riqueza y factores de desarrollo para el sistema productivo: agrícola, servicio doméstico, comercio, etc. ¿Por qué llamarlos trabajos marginales si siguen siendo necesarios? Se trataría de dignificarlos con condiciones laborales dignas. Por ejemplo: ¿Cuantas 
mujeres «modernas» pueden ejercer una profesión fuera de su casa porque en su hogar hay una mujer inmigrante que hace el servicio doméstico y cuida de los niños?... ¿Cuantos ancianos tienen compañía y cuidado porque hay una persona inmigrante a su cuidado? ¿Cuantos hijos están despreocupados porque del cuidado de sus padres ancianos y pueden irse a trabajar porque en casa se ha quedado una inmigrante con ellos?... ¿Por qué no rehabilitar a estos trabajadores y darles "consideración social», además de todos los derechos laborales, si es verdad, que los europeos siguen necesitando que alguien los realice?...

\subsubsection{Los inmigrantes suponen un ahorro importante para el país de llegada,}

Puesto que éste no ha invertido nada ni en su desarrollo, ni en su formación profesional. Es mano de obra adulta y dispuesta para el trabajo, cualificada o no. Por ejemplo: en 1987 casi una tercera parte de los profesionales cualificados africanos vivían en Europa. Entre 1985 y 1990 África perdió unos 60.000 titulados de nivel medio y alto. En 1987 Sudán perdió por emigración el $17 \%$ de sus médicos, el 20\% de sus profesores universitarios y el $30 \%$ de sus ingenieros. En Ghana, el $60 \%$ de sus médicos están en el extranjero. Hay que romper, pues, con la imagen del inmigrante como gente poco cualificada, pobre y marginal.

\subsubsection{Los inmigrantes son trabajadores y profesionales}

Que crean riqueza tanto aquí como en su país de origen. Recordamos que los años 60 y 70, la emigración exterior fue un apoyo fundamental para el desarrollo español, pues las remesas de divisas de los inmigrantes suponían alrededor del $3 \%$ del PIB y del $15 \%$ de la formación bruta de capital. Por otra parte, esta emigración exterior fue una manera de exponer desempleo y gracias a ella la tasa de paro era solamente del $1 \%$ al final del período de los setenta.

$Y$ eso mismo sucediendo actualmente. Por ejemplo, en 1993 los emigrantes marroquíes en Europa habrán enviado a su país unos 175.000 millones de pesetas, lo que equivale al $23 \%$ de los ingresos corrientes de Marruecos y supone el doble de los ingresos de ese país en turismo o en fosfatos en dicho año. En los 80 estas divisas de inmigrantes ya habrán servido para cubrir entre el $20 \%$ y el $40 \%$ de las importaciones totales de Marruecos.

¿No se dice que hay que ayudar al desarrollo de los países empobrecidos? Pues he aquí una forma mucho más racional y digna que otro tipo de ayudas humanitarias o de cooperación. La inmigración es una forma de desarrollo, como decíamos antes. Después del petróleo, las remesas de divisas de los inmigrantes son el ingreso más importante en todo el mundo, más que los créditos FAD (Fondo de Ayuda al Desarrollo).

\subsubsection{Los inmigrantes son productores, consumidores y contribuyentes}

No son parásitos, ladrones, ni delincuentes. No «rebajan» el nivel de bienestar europeo, sino que cooperan a mantenerlo. 
4.2.5.1. Son productores: trabajan, son pequeños empresarios autónomos (por ejemplo, en el centro de Madrid se han abierto más de 300 pequeños comercios por inmigrantes), dan empleo a otros, son personas cualificadas profesionalmente, etc.

4.2.5.2. Son consumidores: fiscalmente son fundamentales y hasta "salvadores» (como veíamos antes en le caso de Italia), pues tienen un efecto saludable en países envejecidos. Lo inmigrantes pagan sus impuestos (de lo contrario les retiran el permiso de residencia) y no reciben mucho a cambio.

4.2.5.3. Socialmente, la inmigración pone sobre la mesa un tema muy importante: avanzar y profundizar en el concepto de ciudadanía europea. Es un hecho que los inmigrantes no somos ciudadanos de pleno derecho. Ahora Europa tiene la oportunidad de construir una ciudadanía más global, más plena y mejor que los conceptos anteriores. Conceder la ciudadanía a cuantos residen en un país sería un gran gesto de salud social. He aquí uno de los puntos débiles de la democracia: limitar determinados derechos únicamente a los nacionales y excluir a los demás.

Es preciso ir configurando un nuevo concepto de ciudadanía, que incorpore a su código de garantías el derecho de minorías. Esto nos obliga a revisar y volver a formar tanto nuestros conceptos de vida como los jurídicos. Es decir, se ha de producir una modificación de las estructuras legales e incluso una rela- tivización de la cultura europea y de algunos de los considerados hasta ahora pilares de la identidad también europea. En la historia de Europa se tardó mucho tiempo en alcanzar el estatuto de ciudadanía por y de las mujeres. ¿Cuánto tiempo estarán excluidos de dicho estatuto los extranjeros inmi-grantes?

4.2.5.4. Culturalmente, la inmigración diversifica y enriquece a la cultura del país de llegada. La diferencia es siempre enriquecedora porque, aunque el cruce es fuente de conflictos, es también fuerza de avance. La diversidad cultural es positiva porque evita los riesgos de la homogeneización: lo que se cree puro conduce al fascismo y al imperialismo, a la imposición. La diversidad es positiva también porque la cultura es algo creativo: a más cultura, más soluciones, más ideas, más alternativas. Las migraciones aportan mucho en plan cultural, artístico y literario. Por ejemplo, ¿qué sería de tantas y tantas manifestaciones culturales, artísticas, deportivas, literarias, etc. si se excluye a las personas extranjeras?...

Las personas inmigrantes enriquecen y complementan a los europeos con sus propios valores culturales. Algunos de estos valores estaban presentes en la propia cultura europea y los van perdiendo por culpa de la uniformidad que les impone la modernidad, la sociedad de consumo y la exigencia tecnicista, que les van haciendo necesitar y comprar todos lo mismo en todo el mundo.

Cuando los europeos se ponen en relación abierta con los inmigrantes reciben de ellos valores tan fundamentales 
como: el sentido de la familia, el respeto a los ancianos, la solidaridad y la hospitalidad que se da entre ellos, el sentido religioso que abarca toda la vida, el poco, el amor a sus raíces, el sacrificio y el esfuerzo por los suyos, etc.

¿No haría falta a los europeos recuperar algunas dimensiones de estos valores que ya están perdiendo o están a punto de olvidarlos por completo?... ¿No habrían dejado algo importante en el camino de la «modernidad» y tendrán que volver a buscarlo?... ¿Tan orgullosos y satisfechos se sientan con su propia civilización?...

Es una posibilidad de un camino inexplorado que se nos ofrece: la interculturalidad. Esta la entenderemos como la capacidad de saber leerse dentro de un conjunto. Porque cada cultura es como una sílaba de la palabra total.

Ninguna por sí sola es capaz de dar una explicación definitiva, pues cada una es como una provincia, pero no puede pretender ser el mundo entero. Los pueblos cerrados no tienen futuro. Abrirse tampoco es fácil. A lo más que se llega hoy es al sincretismo cultural, o sea, a una mezcla confusa de todo, sin coherencia y muy superficial.

Para que exista verdadera interculturalidad es necesaria la reciprocidad, reconocer y aceptar el valor de la parte del otro. Una auténtica interculturalidad nos debería llevar hacia una gran meta: Unir sin confundir y distinguir sin separar. $^{5}$

«Esas gentes eran a pesar de todo una solución» dice Cavafy hablando de los bárbaros cuando fueron infiltrándose por las fronteras del imperio romano. Los inmigrantes son, a pesar de todo, una parte de la solución. Por proximidad, por interpelación mutua y por comunidad de destino, los autóctonos y los inmigrados estamos llamados a tomar conciencia de que ha llagado el tiempo de inventar una nueva manera de ver y de verse. Trabajar la mirada es trabajar los hábitos, los prejuicios, los típicos, los modos de pensamiento, los estereotipos. Es trabajar para transformar la diferencia en riqueza y caminar así hacia un porvenir capaz de un equilibrio social nuevo entre identidad y alteridad, entre yo y tú, entre nosotros y los otros.

Para una lectura seguida y con el objetivo de entender mejor la inmigración y sus corolarios a continuación el autor agrega un artículo anexo al respecto.

\section{Conceptos de racismo y xenofobia dentro de la realidad migratoria con el fin de «Unir sin confundir, distinguir sin separar»}

El apartado de enlace que nos toco tratar irá repleto de definiciones y el criterio que, según la mayoría de la gente, guía parte de nuestras actuaciones en las relaciones intergrupales, respecto al término «raza», tan discutido, factor de categorización social en diversos contextos sociales con su correspondiente carga valorativa.

No ignoramos que en la actualidad el término raza genera polémica y es tan 
controvertido, sin embargo la trataremos desde la percepción de diferencias de valor entre grupos, como factor determinante para explicar cualquier proceso en las relaciones intergrupales en la sociedad.

En esta línea estriba la afirmación de Levis-Strauss (1983) de que

"son las formas de cultura adoptadas aquí $y$ alli por los hombres, sus estilos de vida, tal como han prevalecido en el pasado o siguen prevaleciendo en el presente, los que determinan en una medida muy amplia el ritmo de su evolución biológica y su orientación. Más que preguntar si la cultura es o no una función de la raza, nosotros descubrimos que la raza o lo que generalmente se entiende por tal es una función, entre otras muchas, de la cultura» ${ }^{6}$.

\section{5.l. Delimitación de conceptos}

\section{Estado de la cuestión:}

Rompiendo con los estereotipos, prejuicios y los tópicos se puede llegar a una convivencia enriquecedora y a una integración sin demasiados choques.

\section{5.l.l. La integración}

Incorporación de los elementos étnicos o religiosos dispares de una determinada población a una sociedad uniforme que proporciona igualdad de oportunidades a todos sus miembros. En este tipo de sociedad a ningún miembro se le podrá negar en limitar por razón de sexo, raza, religión o nacionalidad su derecho a recibir educación, acceder a instalaciones públicas o privadas, solicitar un empleo o poseer una propiedad.
Prejuicio, juicio u opinión preconcebida y arbitraria que tiene por objeto a un apersona o a un grupo y puede ser de naturaleza favorable o adversa. Actualmente este término indica, en la mayoría de los casos, una actitud desfavorable hostil hacia personas que pertenecen a un grupo social o étnico diferente. La característica diferenciadora de un prejuicio es que se basa en estereotipos relativos al grupo contra el que va dirigido.

En historia abundan los ejemplos de prejuicios. En mayoría de los casos este tipo de actitud mantenida por un grupo étnico dominante contra una minoría o grupo marginal de la misma sociedad da lugar a diferentes formas de discriminación. El tipo más sofisticado de discriminación es la segregación (aislamiento de diferentes grupos étnicos apoyado por la ley o la costumbre, o por ambos a la vez). Entre los ejemplos de segregación formal se encuentra el confinamiento de judíos en guetos en la Europa medieval y la legislación de estricta separación de razas mantenida por la política de apartheid recientemente abolida en Sudáfrica. Pero el término de segregación también puede aplicarse a la prohibición informal a miembros de una minoría de acceder a clubes sociales, a ciertos tipos de trabajo o a oportunidades de educación.

La integración puede llevar a una rápida desaparición de los prejuicios según la teoría de que el contacto prolongado entre las personas destruye los estereotipos. Existen pruebas de que la mezcla entre miembros de diferentes grupos sociales o étnicos puede reducir los pre- 
juicios, pero en algunos casos este progreso queda limitado al cambio en el que tiene lugar el contacto. Por esta razón, en la práctica, los prejuicios de una sociedad resultan extremadamente difíciles de erradicar, aun cuando la legislación apoye la integración de los diferentes grupos.

\subsubsection{El racismo}

Teoría fundamentada en el prejuicio según el cual hay razas humanas que presentan diferencias biológicas que justifican relaciones de dominio entre ellas, así como comportamientos rechazo o agresión. El término «racismo» se aplico tanto a esta doctrina como al comportamiento inspirado en ella y se relaciona frecuentemente con xenofobia y la segregación social, que son sus manifestaciones más evidentes.

Segregación racial. En 1957, el gobernador de Arkansas (EEUU), Orval Faubus, ignoró las órdenes en contra de la segregación racial y se negó a la integración de los estudiantes de color en los centros de enseñanza de Little Rock. Inmediatamente ordenó a la Guardia Nacional de Arkansas que impidiera a estos estudiantes entrar en la Central High School. El presidente Dwigh Eisenhower respondió con el envío de tropas federales para asegurar el ingreso de estos jóvenes, pero muchos de ellos no fueron admitidos en las escuelas públicas de Arkansas hasta un año después. En 1958, el Tribunal Supremo de Estados Unidos, en el caso Cooper V. Aarón, decretó el final de la segregación racial en esta localidad de Arkansas.

\subsection{En el transcurso de los tiem- pos: raza e historia}

Raza e Historia es un famoso ensayomanifiesto que el antropólogo francés Claude Levis-Strauss escribió en 1952 por encargo de la UNESCO para contribuir al programa de lucha contra el racismo. El capítulo primero, "Raza y cultura», es un escrito clásico sobre el racismo como "teoría y práctica indefendibles» y carentes de fundamento científico. En este capítulo Levis-Strauss es capaz de vislumbrar otras cuestiones que hoy son igualmente graves y urgentes, como los conflictos que surgen por las diferencias culturales entre los múltiples y variados grupos étnicos de todo el mundo.

\subsubsection{Lo que se plasmó en los origines históricos}

La evolución de las culturas muestra que el fenómeno del racismo encuentra su fundamento en la concepción que los hombres tienen de la diversidad. De ello dan claro testimonio los sentimientos de xenofobia que desatan las luchas étnicas o tribales.

En la Grecia antigua la afirmación de una identidad colectiva por oposición a algunas etnias y aciertos grupos de población, se traducía en el hecho de que los habitantes de las ciudades llamaban «bárbaros» a aquellos que vivían fuera de los límites del mundo griego.

La antigua práctica de la esclavitud y de servidumbre ilustra igualmente las relaciones de dominio que han existido en el curso de la historia en etnias y pueblos diferentes, o incluso dentro de so- 
ciedades y grupos culturales. Señores y esclavos podían pertenecer a un mismo origen étnico, pero las diferencias sociales estaban claramente marcadas: los esclavos no tenían derechos, ni siquiera el de ciudadanía. La misma regla se aplicó a la esclavitud. Este último ejemplo, en el que la opresión se ejerce sobre grupos humanos específicos, culturalmente diferentes de sus opresores, se corresponde con las tesis racistas formuladas en la época moderna y su práctica.

Las primeras colonizaciones marcan el principio de la servidumbre de etnias específicas que iban a convertirse en pueblos dominados, forzados a inclinarse ante una voluntad externa. Al extenderse el colonialismo, Europa se arrogó una misión cultural, adoptando como vocación ideológica la educación social y religiosa de los pueblos llamados «salvajes», cuya cultura fue sistemáticamente ignorada y abocada a la desaparición. El progreso científico y técnico que tuvo lugar en Europa contribuyó a reforzar el sentimiento de superioridad de los occidentales, que consideraron su supremacía como natura la su civilización.

La colonización de la América del Norte y del Sur, así como la de Australia entre los siglos XVII y XVIII, la política colonialista de Japón a comienzos del siglo XX o el Holocausto en Europa, son otros tantos ejemplos de racismo.

\subsubsection{Doctrina o dogma acerca de la cuestión}

Los principales elementos fundadores del racismo, que surgieron durante el periodo de colonización, son la conciencia de la identidad cultural propia de cada pueblo, la introducción de la jerarquía en estas culturas y, en consecuencia, el establecimiento de relaciones de dominio entre esos pueblos. A la afirmación de superioridad de ciertas civilizaciones sobre otras, se añaden en los siglos XIX y XX las teorías que asimilan esta jerarquía a un determinismo natural fundamentado en el concepto de raza.

Desde el siglo XVI, sociedades que se proclamaban científicas han buscado clasificar las razas humanas intentando crear estereotipos. La arbitraria clasificación de los hombres en distintas razas en función del aspecto exterior y de las capacidades de inteligencia da pie a teorías como la del diplomático y filósofo francés Gobineau ${ }^{7}$ en el siglo XIX. En su Ensayo sobre la desigualdad de las razas humanas (1853 - 1855), aparecido cinco años después de la abolición de la esclavitud en las colonias de Francia, achacaba el declive de la sociedad al envejecimiento de las razas. El pensamiento racista, contemporáneo del darwinismo social, se va estructurando poco a poco en doctrinas que preconizan la eugenesia, es decir, la aplicación de leyes biológicas al perfeccionamiento de la especie humana. Gustave le Bon sostenía que los extraños alteran el alma de los pueblos y Houston Stewart Chamberlain, que el peligro procedía del caos. El antisemitismo que representa una de las formas más extremas y violentas del racismo, llegó al paroxismo con el nacionalsocialismo, responsable del genocidio de los judíos durante la II Guerra Mundial. La valoración sistemá- 
tica de la idea del dominio de una «raza superior», que constituía la base ideológica del Holocausto, engendró fenómenos de rechazo (segregación, creación de guetos), de avasallamiento (trabajos forzados), de expulsión (desplazamiento de poblaciones) y finalmente llevó al genocidio.

Por regla general, este sentimiento de superioridad va acompañado de la convicción de que las otras razas suponen un peligro, o son susceptibles de generar desórdenes sociales. Este prejuicio se apoya en el conocido mecanismo de búsqueda de una víctima propiciadora. Se convierte a un grupo social en responsable de las crisis económicas y políticas, y se le acusa de ser un elemento naturalmente perturbador.

\subsubsection{A pesar de todo surge el anti- racismo}

Discriminación racial se puede leer en algunas portadas de moteles o hostales "se alquilan habitaciones. No se admiten personas de color». El letrero ubicado en esta portería a principios del a década de 1960 es un ejemplo de la permisividad que existía en la expresión pública del racismo, antes de que se introdujera en Gran Bretaña la legislación antirracista. (Shelton Taylor y Malcolm Aird / Hulton Deutsch).

A principios del siglo XX tuvo lugar una toma de conciencia internacional del fenómeno del racismo. Los procesos de Nuremberg a los criminales de guerra nazis crearon una situación psicológica y política decisiva en la sociedad actual aún perduran numerosas formas de racismo, a pesar de las exhortaciones del os organismos internacionales y especialmente de los acuerdos alcanzados respecto a los derechos de las minorías y de las personas. El apartheid en África del Sur ha ignorado estos acuerdos sistemáticamente hasta 1990. La masacre de la minoría tutsi en Ruanda en 1993 y la «limpieza étnica» emprendida por los serbios en la antigua Yugoslavia a partir de 1991, son claras violaciones de los acuerdos internacionales.

Aunque el racismo no se haya erradicado, la ideología en la que se basa ha sido sometida a una crítica radical en la Segunda mitad del siglo XX. La ciencia ha rechazado el concepto de raza poniendo en evidencia su carácter subjetivo, basado en prejuicios. Antropólogos biólogos, genetistas y sociólogos han demostrado que la noción de raza carecía de sentido en la medida en que el género humano es uno e indivisible.

\section{Aproximación y explicación de algunos términos}

\section{6.l. Minoría}

Muchos investigadores han hecho una distinción entre grupos sociales o categorización social y grupos minoritarios (Morris, 1968). Tal diferenciación radica en la implicación que para el sujeto supone tal pertenencia. En una simple categorización social pueden asignarse rasgos comunes y compartidos por el mismo grupo con un sentimiento neutro en el contexto, mientras que la formación de un grupo minoritario además de ser una categorización en la que se comparten atributos comunes se refle- 
jan en unos aspectos motivacionales y evolutivos muy intensos, de tal forma que poseen una fuerte conciencia de construir una minoría y de la existencia de unos trazados límites con otros grupos, percibido de igual forma por el grupo mayoritario.

Los grupos étnicos se han definido por su identidad social, nacional, lingüística y cultural, percibiéndose de acuerdo a tal caracterización como diferentes, La pertenencia ha guiado sus formas de pensar, sentir y actuar.

Desde un punto de vista social las minorías étnicas han sido calificadas como grupos cuyos miembros unidos por lazos comunes de raza, nacionalidad o cultura comparten unas cualidades infravaloradas por el grupo dominante de la sociedad, transmitiéndose sus desventajas de generación en generación. La organización y cohesión grupal es uno de los factores que determina la influencia del grupo minoritario en las relaciones intergrupales y la concesión de ciertos derechos y deberes.

\subsection{Racismo}

Se dice d este concepto debe ya desaparecer puesto que el único que se pretende con su uso es justificar relaciones de dominancia, resolver conflictos de valores y perpetuar la significación social del término raza.

Nuestro discurso en este concepto no va atender tanto a los rasgos morfológicos y funcionales característicos de una raza y su herencia, sino que vamos a centrarnos en una definición que considere el racismo como una conducta precedida por un proceso cognoscitivo y afectivo donde los factores históricoculturales desempeñan la función principal en el fenómeno de discriminación o categorización social.

Dollar (1988) definió el racismo como el conjunto de prejuicios y actitudes que desarrollan ciertas emociones hacia los grupos; no se trata de una racionalización de la situación de dominio.

Manconi (1989, cit. Por Javier de Lucas, 1992) hablaba de este concepto como una actitud defensiva y / o discriminativa respecto a categorías sociales desarrolladas a partir de una pertenencia territorial y su identidad étnica específica: las manifestaciones racistas ignoran cualquier factor de personalidad o especifidad.

A pesar de tantos tipos de racismos como se han descrito vamos a limitarnos a definir el que nosotros entendemos que impera en la ideología moderna de la sociedad actual. Nos estamos refiriendo al racismo simbólico. Se trata de un prejuicio racial, inmerso en la estructura social, que percibimos que no existe. Este racismo proviene de una pérdida de significado de lo que ocurre en la sociedad occidental, necesitando que nos ayuden a reconstruir dicha pérdida. Se acusa a determinados grupos de violar y pervertir los valores, de aprovecharse del Estado y no esforzarse por méritos personales. El grupo dominante teme que tales grupos consigan esa movilidad que no les es legítima conseguir al no aceptar la competencia individual. Con esta actitud se ha pasado a una forma sutil de discriminación, y que como muy bien ha defini- 
do Dumont (1987), el racismo se ha convertido en un sistema de ideas y valores característico de las sociedades modernas.

\subsection{Xenofobia}

Ha sido definido como una forma de rechazo e intolerancia de toda identidad cultural ajena por el simple hecho de ser diferente a la de otro grupo de civilización. La xenofobia es el miedo al riesgo de la mezcla.

\subsection{Discriminación}

Es aquel comportamiento hostil hacia personas de otros grupos derivado de situaciones de dominación y jerarquía social. Las posibilidades de acción quedan limitadas por su condición de pertenencia y no por sus cualidades individuales. Es considerada consecuencia de los prejuicios, es decir, su comportamiento conativo.

Promueve un conjunto de restricciones que exigen a igualdad de circunstancias diferente escolaridad, inseguridad para el futuro y escasez de oportunidades para la promoción social, creándose un clima de marginación o exclusión que llegamos a percibir como normal.

\subsection{Etnocentrismo}

Fue Williams Graham Sumner en 1906 quien por primera vez definió este término refiriéndose a la actitud con la que percibimos a nuestro grupo centro de todo lo existente y en base al cual evaluamos y valoramos a todos los demás, exagerando diferencias intergrupales para desarrollar una autoestima favora- ble individual y entidad grupal,, fortaleciendo de esta forma cada cultura nacional.

Después de Sumner muchos investigadores se han centrado en el desarrollo de formas etnocéntricas y qué condiciones determinan en mayor medida la manifestación de éstas. Todas ellas han concluido en que se trata de una tendencia a exagerar la superioridad del grupo étnico del Norte con el de Sur imponiendo sus normas grupales como las que deben ser seguidas por el resto de los grupos.

La orientación psicoanalítica defiende que los estereotipos surgen para satisfacer necesidades inconscientes, mientras que desde el punto de vista sociocultural se habla de normas existentes a partir de la cultura e historia que podemos calificarlos como de prejuicios, aprendidos a través de un proceso de socialización y aculturación Por último la orientación del concepto a través del procesamiento sesgado de la información, infravalorando todo aquel conocimiento que confirme las expectativas que definen al estereotipo, para tal fin llevamos a cabo el proceso de selección perceptiva (Billig, 1984).

Por último señalar las aportaciones de otros autores que como J.B. Pontalis y A. Jacquard (1984) niegan que la discriminación, prejuicios, estereotipos, racismo y xenofobia hacia grupos minoritarios étnicos se desarrollen a partir de criterios diferenciadores con éstos, es decir, el racismo no aparece debido a un rechazo radical de las diferencias entre los grupos sino que es la idea de semejanza la que origina los conflictos 
y repercute en las relaciones intergrupales. Julia Kristeva (1988) afirma, por su parte, que el extraño es lo que nos produce esa irritación y reaparición de lo reprimido, es el mismo propio inconsciente contra lo que luchamos cuando combatimos con un extraño, pues éste es nuestro propio inconsciente.

Las definiciones apenas aportan nada sobre la interacción intergrupal, pero son la base para desarrollar nuestras explicaciones y comprender desde que orientación se mueven éstas.

\section{Conflicto interétnico: Perte- nencia grupal y los efectos psisociales de las minorías}

La pertenencia a una determinada categoría implica asignar una serie de atributos grupales que, a diferencia de los individuales, deben ser compartidos socialmente, derivándose de ello consecuencias sociales comunes. La conciencia de ser miembro de un grupo minoritario concreto y la identificación con éste va a depender de la percepción de fronteras con miembros de otros grupos.

Al grupo minoritario se le han impuesto limitaciones de acción y desarrollo atendiendo tanto a diferencias culturales como sociales, políticas e históricas respecto a otros, y a pesar de que el grupo es consciente de tales diferencias y sus efectos, en determinadas ocasiones pueden identificarse con la sociedad en la que se encuentren inmersos y mantener aquellos atributos que para ellos son relevantes.
Las relaciones intergrupales dentro de una sociedad dependen de las condiciones sociales en que viven ambos grupos resultando ser la conciencia de interdependencia y la percepción de un alto nivel de diferenciación entre los grupos los determinantes más importantes de los efectos de pertenencia dados en los grupos minoritarios. Estos comienzan a exigir su derecho de ser diferentes aceptando su pertenencia grupal que les permite definir esa identidad facilitadora, una seguridad sobre quiénes son, qué desean y qué les corresponde obtener por derecho propio. No sólo ya no se rechaza esta diferenciación intergrupal sin que se comienza a no aceptar la posición social en la que les ha tocado vivir y sus consecuentes injusticias percibidas.

A lo largo de la Historia las minorías se han ido definiendo desde criterios utilizados por la mayoría, asignándoles rasgos que infravaloraban a sus miembros. Llega un momento en el proceso de identificación en el que los grupos étnicos minoritarios necesitan valorar positivamente sus cualidades calificadas como inferiores reevaluándose de nuevo éstas para conseguir una diferenciación positiva que solicita una nueva posición en la sociedad.

Puede ocurrir que algún movimiento individual sea posible y se mejore la calidad de vida de alguno de los miembros, sin que por ello se modifiquen las condiciones del grupo ni la actitud de la mayoría ante tales logros. Esta percepción de legitimidad y estabilidad del sistema supone aceptar las diferencias según criterios compartidos por ambos 
grupos. Para que el grupo minoritario perciba alternativas y la posibilidad de cambio social es necesario que observe que es posible llegar a la ruptura de las capas sociales establecidas, percibir que se puede presionar y aprovechar la ocasión para actuar y transformar la situación, para lo cual deben pasar por la fase de rechazo de su status y del sistema de creencias sobre la inferioridad de sus atributos como grupo.

Un sistema de relaciones intergrupales percibido como ilegitimo lleva a un rechazo de la posición social por parte del grupo en desventaja, quedando claro que ocurre esto en un sistema percibido como legítimo e inestable (Turner y Brown 1978, Commins y Lockwood 1979).

\section{El fenómeno de la inmigración. Con el fin de unir sin confundir, distinguir sin separar}

La realidad de las migraciones, vulgarmente conocida como el fenómeno de la inmigración es tema bastante complejo y delicado ya que trata de seres humanos lo cual supone la misma complejidad de la persona. No obstante la calificación de un proceso o fenómeno social denota los múltiples significados e interpretaciones desde los cuales se estudia.

La regulación del fenómeno de inmigración recibe la influencia de toda una sociedad en la que se utiliza la pertenencia grupal e interacción social para salvaguardar los intereses personales, percibiéndose la inmigración como instrumento de cambio de relaciones sociales en un contexto en el que antes que las decisiones individuales para cambiar actitudes es el consenso social el que goza del poder para mantener la igualdad, las diferencias y las relaciones de dominio como consecuencias sociales de la inmigración.

El trabajo en sociedad, sus conflictos sociales, los fenómenos de estratificación y movimientos ascendentes y descendentes, los procesos de seguridad e integración, la tendencia a lo homogéneo de forma grupal, la comunicación entre culturas... aspectos que marcan el carácter social de la inmigración, es decir, nuestros procesos psicológicos son función de todo fenómeno social desencadenado por el fenómeno inmigratorio.

Aspectos como el color de la piel, la cultura, religión o lengua determinan el que la educación no sea impartida al mismo nivel que para otros grupos étnicos diferentes, es decir, todo grupo que se encuentra inmerso en otra cultura diferente a la suya exige una igualdad en el nivel educativo, una participación en el gobierno, mejora de la calidad de vida y una modificación de actitudes hacia determinados grupos mayoritarios que no dejan lugar a cualquier influencia del factor individual por parte de aquéllos, y no cabe duda que la dimensión social determina gran parte de éstos.

La naturaleza de la sociedad a la que llegan los inmigrantes y la orientación de ésta hacia el multiculturalismo determinan tanto el tipo de relaciones en- 
tre las distintas etnias como los canales de comunicación y entendimiento entre ambas culturas, todo ello en función de otro aspecto de carácter social como son las normas que gobiernan las conductas de cada grupo.

La sociedad espera unos comportamientos concretos por parte de todo el grupo de inmigrantes; no va a dejar pasar conductas individuales inaceptables sin hacer referencia al grupo. Van a exigirles lealtad nacional, obediencia a la ley, responsabilidad en cada una de sus acciones, valores comunes que no deben prevalecer a los que definen la cultura del país de llegada, así como una educación y lengua propia de la nación. Todos estos supuestos reflejan un contexto social específico que es necesario analizar en relación con factores educativos, económicos y políticos, es decir, una parte del contexto debe analizarse haciendo referencia a la globalidad de él.

El llegar a entender distintas situaciones socioculturales implica un proceso de aprendizaje afectado por multitud de componentes del estilo de vida y experiencias educativas y culturales, problema social que compete a toda comunidad. El no llevar a cabo este proceso de entendimiento perpetúa la situación de marginación de este colectivo inmigrante que no encuentra ya forma alguna de contribuir al desarrollo de la sociedad en la que desea integrarse, sin embargo en ocasiones se les acusa del desajuste socioeconómico, político y cultural. Una quiebra del sistema que afecta a todo el contexto en general.

El tema de la inmigración nos enfrenta a los problemas de una sociedad que sólo pretende la estabilización de la vida social.

Tanto el grupo de inmigrantes como la población nativa deben pasar por un proceso de socialización en el que traten de integrar imágenes y contenidos culturalmente significativos y específicos en una visión de la sociedad que abarque un concepto de lo multicultural y sus problemas de forma común, con respuestas únicas que respondan a un modelo de desarrollo y convivencia que favorezca el ajuste psicosocial.

\section{Bibliografía explicativa}

BILLIG, M. (1984): «Racisme, préjugés et discrimination », en S. Moscovici (ed.), Psychologie Sociale, PUF, Paris.

CALVO BUEZAS, T. (1995): Crece el racismo, también la solidaridad: los valores de la juventud en el umbral del siglo $X X I$, Madrid, Tecnos.

[Estudio de las actitudes de la juventud ante el racismo y la solidaridad]

DELACAMPAGNE, C. (1983): Racismo y occidente, Barcelona, Argos Vergara.

[Un interesante estudio del desarrollo de las actitudes racistas en la sociedad occidental]

DOLLARD, J. (1988): Caste and Class in a Southern Town, Madison, University of Wuscosin Press.

DUMONT, L. (1987): Essais sur l'individualisme, Paris, Seuil.

DE LUCAS, J. (1992): Europa: ¿Convivir con la diferencia? Racismo, nacionalismo y derechos de las minorías, Madrid, Tecnos. 
GOBINEAU,J.A., Conde de Gobineau (1816-1882). Diplomático y filósofo francés, cuya teoría racial está impregnada de antisemitismo. Su obra más famosa es el Ensayo sobre la desigualdad de las razas humanas dignidad (1853-1855). [Raza superior]

LEMONTIN, R.C. (1996): No está en los genes: crítica del racismo biológico, Barcelona, Gijalbo-Mondadoni.

[Importante estudio crítico contra los fundamentos biológicos del racismo]

LEVIS-STRAUSS, C. (1983 a): Le regard éloigne, Paris, Plon.

LEVIS-STRAUSS, C.(1996 b): Raza y cultura, Madrid, Cátedra.
[Legendario ensayo - manifiesto en contra del racismo y a favor de la diversidad cultural]

KRISTEVA, J. (1988): Etrangers à nousmêmes, Paris, Fayard.

MORRIS. H. S. (1968), Ethnic groups, Internacional enciclopedía of the social sciences, vol. 5. Nueva York, MacmillanFreePress.

PORTALIS, J.B. y Jacquard, A. (1984): Entretien: une tête qui ne convient pas, Le Genre Humain.

SUMNER, G.A. (1906): Folkways, Nueva York, Ginn.

TURNER y BROWN (1978): Social status, cognitive alternatives and intergroup relations.

\section{Notas}

${ }^{1}$ Ministerio de Asuntos Sociales. DGM. «Plan para la integración social de los inmigrantes». 1994.

2 L'USINE NOUVELLE, semanario francés del mes de junio de 2002.

${ }^{3}$ WOOD , B. (2000): «Old and new paradigms in the study of human evolution». Revista de Antropologia, $N^{\circ} 78$, pág. 17 hasta 34

${ }^{4}$ En Diario El País, del 28 de agosto de 1998.
${ }^{5}$ Idea de un autor anónimo de la India contemporáneo R. Tagore.

${ }^{6}$ LEVIS STRAUSS, C. (1983) Race et Culture, PUF, Paris. Edición española (1993) Raza y Cultura, Cátedra,

7 GOBINEAU, de J. A., (1853 - 1855) Essai sur l'inégalité des races humaines en español: Ensayo sobre la desigualdad de las razas humanas. París: Éditions Pierre Belfond [1967], Livre I, Chapitre XVI, p. 198. 